\title{
Determinants of Employee Commitment and Continuous Improvement in Animal Feed Companies
}

\author{
Pedro Manuel do Espírito Santo ${ }^{1}$, Patrícia Milene Azinheira Cardoso ${ }^{2}$ \\ ${ }^{I}$ (ESTGOH - I.P.Coimbra, ESEV - I.P.Viseu, Portugal) \\ ${ }^{2}$ (J. Cardoso \& Filhos, Lda, Figueira da Foz, Portugal)
}

\begin{abstract}
In Portugal, unemployment is high when we compare with other countries and companies do not develop strategies to retain the best employees inside. It is clear that employees are a key part of a company's success, so organizations should look for better ways to hire new talent for business, as well as seek ways to keep the best brains by identifying antecedent variables of commitment of employees. Thus, this study is a contribution to the investigation by the identification of key variables in the commitment of the worker and in the environment of continuous improvement in the companies. Through a study applied to 97 employees, the results show that leadership is the main antecedent of the continuous improvement environment in companies. In addition, this study identifies the worker's well-being and the work-life balance as the major antecedents of the workers' commitment.
\end{abstract}

Keywords: Leadership; Employees; Continuous improvement; Worker's Commitment

\section{Introduction}

Today, quality is a very used term in companies. This is associated with the quality of the product, but also with the quality of the processes. The search for improved customer service is seen as a critical factor in organizations. [4] and [34] indicate that is the development of new solutions that aims to achieve more efficient operations and an superior performance. By the response to the present challenges, globalization and intense competition, it is useful improve companies to open new markets and create greater customer loyalty.

In this context, the feed manufacturers are in a context of aggressive price competition. This context is more agressive by the reduction in the number of existing clients, the abandonment of the small farmer's agricultural activity and the concentration of activity in larger companies. In addition, the market for animal feed has been declining and smaller companies are experiencing difficulties [21]. With this view, the study presented here aim evaluate the impact of the effects of human resources variables in continuous improvement. So, Leadership emerges as an influencer of the business team in order to guide efforts for continuous improvement [12], [31]. The importance of leadership in organizations is high and therefore it is through effective leadership that an organization can significantly improve. Employees are part of the process of continuous improvement in companies and it is they who improve customer service, so employee well-being and work-life balance can improve companies. Considering the challenges, this study aims to study the effects of leadership, worker well-being and work-life balance in continuous improvement in industrial enterprises of compound feed production.

\section{Literature Review}

In literature review we saw leadership style is important because it improves employee relationships, improves organizational culture, and improves performance in organizations. Without followers there are no leaders and the leadership means that there is a relationship between leaders and their followers [33]. Leadership in organizations is sometimes confused with top management. However, at the organizational level, there are some leaders who are not managers of companies and, in some organizations, top managers are not seen as leaders, or their followers do not exist.

Although there are leaders with different profiles in organizations, the most successful leadership is the one with the most followers, so the success of leadership is done by the number of followers. However, the existence of a greater or lesser number of followers depends on their perception of the actions performed by their leaders. The ability of leaders is to mobilize and influence their followers to act consistently with motivation and dedication in order to achieve the established objectives [28]. The leaders have the role to instill principles and responsibilities that motivate their followers to work with interest [31].

Thus leadership is assumed as one of the key variables in management. In this sense, leadership in organizations can lead the organization to success or lead to failure. It is the leaders who are assigned the responsibility of mobilizing their teams in order to achieve organizational goals, whereby the leader's profile has been discussed in the literature over the years. 
The authoritarian profile is a type of leader who reflects characteristics of paternalistic control and submission to authority which, according to [10] the leader considers that the employees do not have ambition. The authoritarian profile is a type of leader who reflects characteristics of paternalistic control and submission to authority which, according to [10] the leader considers that the employees do not have ambitions and, in general, will have to carry out the tasks through co-acted form. The participatory leader is a type of leader who involves the subordinates although the final decision is yours.

Organizational leadership builds on relationships, and the relational leader assumes that there are interactions between people that depending on the context, relationships can create value. So the leadership can be understood as a part of values such as love, motivation, attitudes, beliefs, ethical values and moral values. Leaders are associated with context factors that are considered a key element in motivating employees. It is the leadership in organizations that seeks, through its style of action, to create harmony in teams, improving the team spirit in organizations. Leadership style is seen as effective when organizations want to motivate their teams. According to [1], the existence of a work-life balance will have improvements in the performance of the companies. Work-life balance has been conceptualized as an important phenomenon in the literature and is defined as the satisfaction of the interconnection between good performance at work and the accomplishment of personal tasks with the least conflict. In addition, Work-life balance is seen as the ability to maintain the balance between paid work and personal life beyond that work [29].

Gender is usually a variable that appears associated with work-life balance-related conflicts. Although there is a lot of literature that indicates that gender is irrelevant to the work-life balance for working women we recognize the existence of the impact. Because of their role in society, the female gender has more conflicts between the personal life and the professional life, and in this sense, it is common to see that the family commitment hinders to a large extent the development of the business career [1]. The role of social support or back-up support in employees has grown in the importance of factors that influence worker performance and organizational commitment.

The conflict between roles (home and work) is negatively correlated with job satisfaction, career satisfaction, and positively with increased stress, depression and physical illness [16]; [28]. To improve the balance between the professional and personal tasks of workers, some companies offer a range of benefits. There is the possibility, in some organizations, of job sharing, working in flexible hours, family assistance, childcare at the workplace, support groups for working parents, laundry facilities, canteen facilities. Human resource professionals know that people are at the heart of organizations. People promote innovations, creativity, and intangible contributions to organizations, and to maximize the success of organizations, it must have a climate that supports their performance, but also the welfare of its employees [19].

Recent research has shown that concern for worker health, worker behavior and the value of human capital are related. In a simpler way, it can be said that workers' well-being affects their performance and affects their rates of absenteeism in companies, so developing worker well-being will result in higher productivity [18]; [28].Today, knowledge about the well-being involves a broad concept that includes health and care for the other. This integration approach of welfare, businesses, may be associated with the welfare of workers.

Workers' well-being typically includes some dimensions such as [19]:

- $\quad$ Physical health including the improvement of workers' health;

- Emotional health associated with resources to balance the worker with others;

- $\quad$ Financial health that is defined as the freedom and success of workers.

Companies are integrated different types of people with different interests. The existence of these interests is distinguished by how the worker is integrated into the organization and the way the worker sees the organization as yours. The integration of employees in the company can be a very important variable in determining the commitment of the employee to the company [18]. Organizations have goals and targets and the workers intend to be in environments that feel more identified and comfortable. Thus, the worker's commitment is defined in terms of feelings or emotional attachment. A worker's commitment to his or her organization can be seen as a multidimensional construct that can be distinguished from definitions in the literature of commitment. Of these components, the commitment can be distinguished between [13]; [26]; [28]; [33]:

- Affective commitment that reflects some sort of emotional attachment to the organization;

- Continuation commitment that is associated with the costs that the worker will have in leaving the organization;

- Normative commitment that is related to the moral obligation to continue to collaborate with the organization.

Nevertheless, the worker's commitment, regardless of its size, is associated with higher levels of performance. Some authors indicate that the worker's commitment has as background demographics [3]; [18]; [22]. However, increasing age positively influences the worker's commitment, by the lack of alternatives that older workers have in the labor market, so these workers are more committed to the organizations where they work. 
Moreover, the worker's expectations are also a variable to consider. Workers will be more committed to the company if there is a clear correspondence between what the worker expects and what the company can offer. In addition to the listed variables, some authors report that the quality of the relationship between managers and their workers is related to the development of commitment. Employees who have good relationships with managers will be more committed to the organization. In addition, effective communication at work is an essential ingredient in business performance [26].

Therefore, this study seeks to test the following research hypothesis:

H1: Leadership has positive effect on worker's commitment

Training is an important part of the commitment process with the company. The existence of recognition of workers' needs in growing the organization to the intellectual level and recognition of efforts by companies to seek more appropriate training to people's needs can be an important step to increase the commitment of employees in undertakings [6]. In this follow-up, also communication with colleagues provides an emotional attraction to the workplace, so the existence of a fruitful communication in the workplace increases in part the commitment of workers [18].

There is argument in the literature for employees that the existing justice in the organization is part of a way to build commitment. Justice is related to the concept of trust and this trust will cause a higher level of commitment to the organization where it collaborates, which can increase performance in the organization. Furthermore, the existence of promotional policies, acknowledgment is associated with higher levels of worker involvement. The development of employees and recognition of the efforts will create a climate conducive to improve the level of relationship between organization and employee. Beyond the listed variables, job satisfaction is seen as a variable with effects on behavior and worker commitment. Employees who enjoy their jobs will continue to be attracted to continuing to work in a company which implies a greater commitment to the organization.

Therefore, this research will seek to test the following research hypothesis:

H2: Workers' welfare has positive effects on their commitment to the company

Commitment comes as an acceptance of the employee's goals and values of the company and the willingness to continue as a member of the organization, stresses that work-life balance improvement programs try to raise commitment to the organization [11], [20].

Thus, this study will try to evaluate the following research hypothesis:

H3: The balance between work and personal life has positive effects on the commitment of the worker to the companies

The companies intend to be the best in their business, however, the ambitions must be realistic according to the resources of the company, so the need to reach the optimum must be realized incrementally. Thus reaching the desired future state depends on steps achieved through small steps [3]; [30]. In companies, the improvement can have as a consequence the reduction of waste, smaller dimensions of re-work, customer satisfaction, employee satisfaction and gain a competitive advantage with other companies. For this reason, continuous improvement initiatives have been increasing in companies from day to day.

Through a high growth of business complexity, in organizations it is not the processes that make difference in competition but the ability to continually improve them. Therefore, [2] report that continuous improvement is defined as the systematic effort to look for new ways of doing the same work. According to the literature continuous improvement is an approximation to represent efforts to seek and apply new forms of Improve the operations of a company [2], making changes to the processes causing improvements. Processes are referred to as desiring sequences of tasks, from the transformation of materials to the exchange of information. Continuous improvement implies a set of practices and tools that are used in the execution of operations.

The focus of continuous improvement may arise through some of the following dimensions [3]; [30]:

- Process - transformations or modifications of added value to the product carried out at the process level

- Coordination - transformations in the flow of materials and information throughout the company's factory or set of factories

- Technology - transformation in the technology used in productive operations, either through the exchange of equipment or even through the reconfiguration of existing technology;

- People - degree of involvement with improvement initiatives in a concerted way

- $\quad$ Product innovation - product-level transformations (re-design, concept, packaging) over a long sustainable period

The benefits of a committed workforce can be reflected in increased employment performance, profitability for the company, the increase in sales, decreased productivity breaks, reduced absenteeism and reduced intention to leave the company. In implementing a total quality management system, it is important to involve all employees in order to develop skills that are fundamental to the process of behavioral, personal and organizational change that total quality management requires. Leadership emerges as a way for a person to act that guides individuals in order to achieve goals in an organization [4]; [12]. 
Thus, this study will try to evaluate the following hypothesis of investigation:

H4: Leadership has positive effects on continuous improvement

Employees should be the innovators of the processes that, through their competence, will be able to obtain better results in the company's performance. Recent research has indicated that the well-being of employees is critical to continuous improvement continue to exist. Thus, as suggests [5], the welfare of employees suggests that they have availability to stay aligned with the company's practices and thus to the business environment.

So, this study will try to evaluate the following hypothesis of investigation:

H5: Workers' well-being has positive effects on continuous improvement

Employees in firms that have greater stability in their lives will be more available to suggest improvements in the firm [34]. [1] emphasizes that the programs that exist in the companies for a better Worklife balance can improve the processes.

Therefore, this study will seek to evaluate the following research hypothesis:

H6: Greater work-life balance, greater organizational improvements

Following the deduction of hypotheses, we present the conceptual model (fig. 1) that through the appropriate methodology is intended to test the research hypotheses.

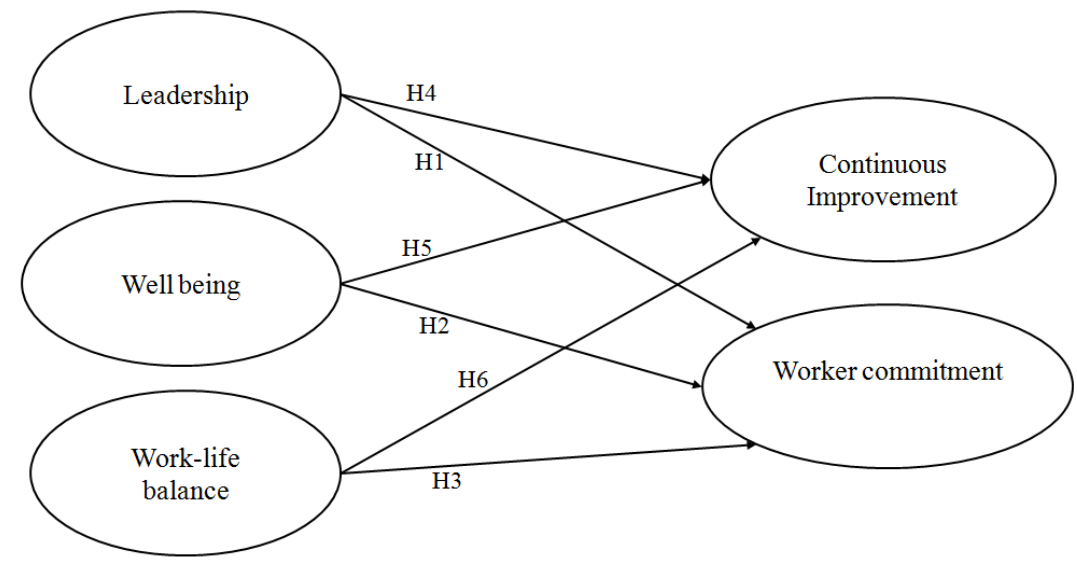

Figure 1 - Conceptual model

\section{Methodologies}

The hypotheses were tested on a sample consisting of employees of industrial companies whose business focuses on the production of compound feed for livestock. This sector has seen sales fall over the last few years, the meat consumption reduction that has been witnessing. This reduction in meat consumption is due to the fact that there are growing concerns about food and health by changing the food pyramid of the Mediterranean diet.

Therefore, the objective of this study is to analyze the variables with impact on continuous improvement in order to understand the variables that can improve the optimization of the company. On the other hand, the objective of the study also aims to analyze the variables that impact the commitment of workers to organizations in which collaborate. Thus, the sample of 97 workers that served as the basis for the analysis of the results is composed of workers from the companies contacted during the year 2014, who accepted to respond to the questionnaire. This questionnaire was self-administered, filled out immediately after it was delivered, and doubts about the issues debated at the time they arose.

\begin{tabular}{|l|l|c|l|}
\hline & & workers & $\%$ \\
\hline Gender & Male & 80 & $82,5 \%$ \\
\hline & Female & 17 & $17,5 \%$ \\
\hline Education & Basic & 57 & 58,8 \\
\hline & Secundary School & 34 & $35,1 \%$ \\
\hline & High Level & 6 & $6,2 \%$ \\
\hline Age & under 30 years old & 18 & $18,6 \%$ \\
\hline & between 31 and 40 years old & 15 & $15,5 \%$ \\
\hline & between 41 and 50 years old & 27 & $27,8 \%$ \\
\hline & between 51 and 60 years old & 32 & $33,0 \%$ \\
\hline & More than 60 years old & 5 & $5,2 \%$ \\
\hline
\end{tabular}

Table 1: Sample characterization 
From the sample it is emphasized that this is mostly composed of men, aged between 30 and 50 years, in most cases. In terms of education, it appears that most of the workers have qualifications at the level of basic education (Table 1). The data obtained through the questionnaire were subjected to statistical treatment and this statistical treatment was developed in three main stages:

- Analysis and Purification of scales;

- Evaluation of the overall measurement model;

- Evaluation of the structural model.

In the first step, through an exploratory analysis, the study began for rating items in the study. In order to do so, a refinement of the scales was carried out in order to analyze its validity and consistency. This step was carried out by analyzing the correlation between each item in the set of items that constitute the scale. This analysis adopted the traditional approach of [8], with the objective of finding a set of items that demonstrate its dimensionality. In this step, an exploratory factorial analysis was performed, followed by an analysis of the Chronbach Alpha coefficients of the extracted factors [9];[17].

Thus, we analyzed the dimensionality of each scale, proceeding to the exploratory factor analysis. This factorial analysis consists of a set of statistical techniques that seeks to explain the correlation between the observable variables, simplifying the data by reducing the number of variables necessary to describe them. This type of analysis presupposes the existence of a smaller number of unobservable variables underlying the data (factors), which express what is common in the original variables, allowing to evaluate the validity of the variables that constitute the factors, indicating whether or not they measure the variables [27]. Thus, it was possible to analyze the correlation structure of the items through the exploratory factor analysis. This exploratory analysis sought to obtain factors common to the items through an orthogonal rotation - varimax and extracting the number of factors whose mean variance explained was above $50 \%$ as suggested by the literature [17]; [27]. This exploratory stage identified items whose relationship with the latent variables was weak, so that the items did not present higher correlation of 0.50 with the construct that sought to measure were eliminated from the study because they are not responsible for, at least, $25 \%$ of the explanation of the concept [27]. After exploratory factor analysis and before testing the structural model model must first be examined on the measures that make up the concepts in a comprehensive manner.

This analysis should be done to evaluate whether the measurement model adequately describes the data collected from the sample and to evaluate if the concepts are reliable [25]; [32]. The analysis of the concepts that make up the model of global measures reveals that the concepts under study have factorial validity. This arises because the standardized coefficient obtained for each item to be greater than 0.5 in all items that measure the constructs [14];[17], as shown in Table 2: measurement model results In addition, to assure factorial validity, it will be necessary to evaluate Student's t values, which show that the items used to measure the constructs are significant at $\mathrm{p}<0.01$. Thus, it is considered that the measurement model has validity. Since the factorial validity is checked, we follow by the evaluation of convergent validity. This analysis seeks to evaluate whether a variable is being measured properly for their items. Thus, following the literature [17]; [24]; [25] and by analysis of table 2: Measurement Model Results. It is verified that the composite reliability is higher than 0.7 as suggested in literature [14] and also the mean extracted variance is greater than 0.5 in all constructs, so we concluded by the global measurement model validity.

Table 2: Measurement model results

\begin{tabular}{|c|c|c|c|c|c|c|c|}
\hline & Mean & Std Dev. & $\lambda$ & $t$ Values & $\begin{array}{c}\text { Average Variance } \\
\text { extracted }\end{array}$ & $\begin{array}{c}\text { Composite } \\
\text { reliability }\end{array}$ & $\begin{array}{c}\text { Cronbach } \\
\text { Alpha }\end{array}$ \\
\hline Leadership & & & & & 0,657 & 0,882 & 0,833 \\
\hline Leader 01 & 3,321 & 0,983 & 0,868 & 30,165 & & & \\
\hline Leader02 & 3,393 & 1,031 & 0,878 & 31,227 & & & \\
\hline Leader03 & 3,536 & 0,881 & 0,870 & 34,305 & & & \\
\hline Leader04 & 2,500 & 1,000 & 0,591 & 6,798 & & & \\
\hline Well Being & & & & & 0.719 & 0.885 & 0.804 \\
\hline Well Being 01 & 3,286 & 0,976 & 0.750 & 9.798 & & & \\
\hline Well Being 02 & 3,321 & 1,020 & 0.899 & 36.974 & & & \\
\hline Well Being 03 & 3,393 & 0,875 & 0.888 & 33.073 & & & \\
\hline Work life balance & & & & & 0.774 & 0.911 & 0.854 \\
\hline Worklife 01 & 3,393 & 1,100 & 0.895 & 31.087 & & & \\
\hline Worklife 02 & 3,393 & 1,066 & 0.884 & 21.533 & & & \\
\hline Worklife 03 & 3,571 & 0,959 & 0.860 & 23.468 & & & \\
\hline Worker's commitment & & & & & 0.768 & 0.869 & 0.699 \\
\hline Comm01 & 3.964 & 0.744 & 0.885 & 8.924 & & & \\
\hline Comm02 & 4.500 & 0.694 & 0.869 & 14.535 & & & \\
\hline Continuous Improvement & & & & & 0.721 & 0.886 & 0.806 \\
\hline Improv01 & 3.929 & 0.875 & 0.866 & 45.727 & & & \\
\hline Improv02 & 3.857 & 0.803 & 0.869 & 28.897 & & & \\
\hline Improv03 & 3.929 & 0.663 & 0.811 & 26.820 & & & \\
\hline
\end{tabular}


Since the factorial validity Convergent validity is verified, the evaluation of the overall model measures continued with the analysis of discriminant validity. Thus, as a third step in the evaluation of measures model was followed by the analysis of discriminant validity trying to evaluate whether the measurement model, the concepts that make this model will be distinct from each other.Thus, by analyzing table 3 , it is verified that the mean extracted variance, whose values are presented in the main diagonal, is in all cases, superior to the square of the correlations between the concepts under analysis. Therefore, there is evidence to conclude that the concepts have discriminant validity. The discriminant validity arises as a prerequisite for a correct assessment to the validity of the structural model, so that it may proceed with the analysis for the evaluation of the structural model.

Table 3: Correlations - Discriminant validity

\begin{tabular}{|l|c|c|c|c|c|}
\hline & Leadership & Well being & Work life balanace & Commitment & Continuous improvement \\
\hline Leadership & 0,657 & & & & \\
\hline Well being & 0,441 & 0,719 & & & \\
\hline Work life balanace & 0,268 & 0,248 & 0,774 & & \\
\hline Commitment & 0,078 & 0,101 & 0,079 & 0,768 & \\
\hline Continuous improvement & 0,572 & 0,289 & 0,208 & 0,136 & 0,721 \\
\hline
\end{tabular}

Note: Average Variance extracted (AVE) in diagonal

After the evaluation of the overall model measures, the methodology has by analyzing the structural model, seeking to test the research hypotheses. In this context, an estimated parameter is consistent with the theoretical considerations are significant in the investigation must be regarded as admissible, leading to the research hypotheses are supported. As a complement, it should also be analyzed t Student's value to evaluate their statistical significance of the parameters to consider significant. In addition, associated with this analysis should also consider the $\mathrm{R}^{2}$ value for each structural equation considered, similar to that used in multiple linear regression.

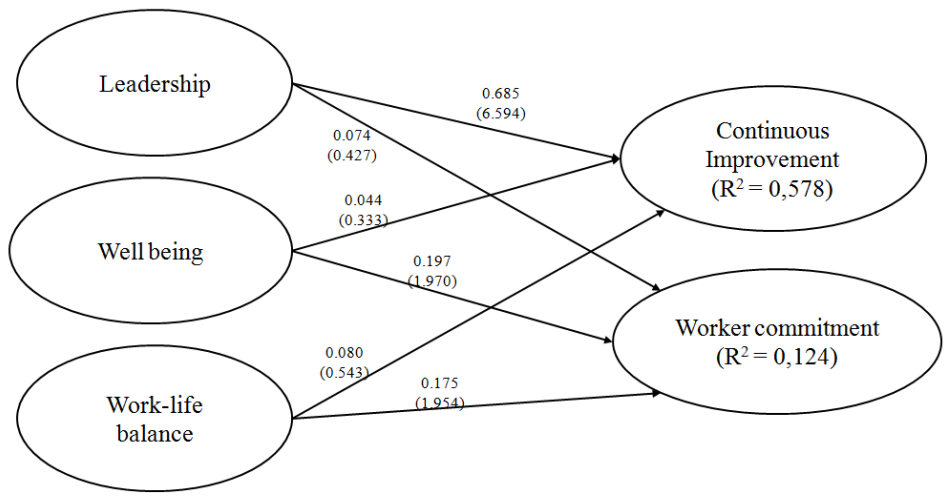

Figure 2 - Structural model results

In Figure 2 - results of the structural model, the model extracted from SMART PLS software is represented, where each coefficient intends to represent the relation between two concepts. The numbers presented represent the intensity of the relationship, while the value within the circles represents the value $R^{2}$. Thus, it can be verified by the results that the commitment of the workers in the companies is explained in part $\left(\mathrm{R}^{2}=0,124\right)$ by the variables that have significant relations. Thus, there is an explanatory relationship between workers' well-being and workers' commitment $(\beta=0.197, \mathrm{t}=1.970)$ and there is also a positive relationship between work life balance and workers' commitment $(\beta=0.175 ; \mathrm{t}=1.954)$.

It is also verified that the initiatives of continuous improvement are realized mainly through the positive effects that the leadership demonstrates $(\beta=0.685 ; \mathrm{t}=6.594)$.

\section{Discussion}

Through the presentation of the results, we will discuss them based on existing literature. The H1 research hypothesis seeks to evaluate the effect of leadership on worker commitment [15]. Although the literature indicates that the relationship exists, this study does not support this hypothesis. Thus, no corroboration of this hypothesis may be related to the vision of organizational leaders who are not seen as such, ie, they do not have many followers in companies, so that the commitment does not appear as evidence. Thus, this study does not allow to corroborate the H1 hypothesis. However, the well-being of workers is directly and positively related to workers' commitment, which is corroborated by the $\mathrm{H} 2$ hypothesis. This relationship exists because, according to the literature, a worker who feels good in the business environment will be more available 
to be satisfied with the company and the job, which translates into greater trust and commitment to the company [15]. As in the previous case, $\mathrm{H} 3$ is evidenced by this study. This statistical support, evidenced by the results, demonstrates that the existence of lower levels of conflict between personal and professional lives of employees of enterprises, results in a larger relationship with the company and, consequently, a greater commitment to the company [18]. Therefore, from the antecedent variables of continuous improvement only leadership has significant direct effects. These results, this study follow other studies [12]; [23]; [31], such as, that indicate that organizational leaders have the ability to continually improve organizational performance. This happens because they are the leaders in the companies, through the harmony created in their teams that effectively improve the companies and their processes. Thus, it will be permissible to say that through leadership in companies seeking employees indicate opportunities for improvement, learn new working methods and develop teamwork. This study corroborates the H4 hypothesis.

Hypothesis H5 is not supported by this study since the relationship between worker well-being and continuous improvement does not have significant statistical evidence. These results may be associated to the items that were used to measure workers' concept of well-being, which this concept is reflected in the physical health care of the worker [19] and in the care of the other, which may not have direct effects on how corporate employees seek to improve their organizational capabilities.

Continuous improvement does not appear to have significant direct effects of the work life balance. This result may be associated with the way it views the work life balance. In this respect, gender is a variable associated with conflicts between personal and professional life for the role that women play in society. In this study, due to the characteristics of the sample, it is verified that the majority of respondents is male, which may not have allowed more meaningful conclusions to be drawn. And then, the H6 research hypothesis is not supported by this study, since the direct effects between work-life balance and continuous improvement are not significant. In this regard, Table 4 shows the result of the confirmation of the hypotheses under study.

Table 4 - Hypotheses Confirmation

\begin{tabular}{|c|c|}
\hline & Hypothesis \\
\hline H1: Leadership $\rightarrow$ Worker's Compensation & Not Supported \\
\hline H2: Workers 'Well-being $\rightarrow$ Workers' Commitment & Supported \\
\hline H3: Work life balance $\rightarrow$ Worker commitment & Supported \\
\hline H4: Leadership $\rightarrow$ Continuous Improvement & Supported \\
\hline H5: Workers' Welfare $\rightarrow$ Continuous Improvement & Not Supported \\
\hline H6: Work life balance $\rightarrow$ Continuous Improvement & \\
\hline
\end{tabular}

\section{Conclusion}

The purpose of this study was to analyze the variables with effects on the continuous improvement and the commitment of the workers in the companies. From a theoretical perspective, this study has as contributions to the scientific community corroboration of the hypotheses studied identifying organizational leadership as a key variable of continuous improvement. This study also suggests that the workers' commitment has as antecedents their well-being and the work life balance.

On a more practical level, further conclusions may be drawn. Companies may be offered practical development options to improve employee commitment and their concern for continuous improvement and according to the results of this study, to increase the levels of employee commitment in companies and they should develop mechanisms to increase workers well-being. Thus, companies can create mechanisms to improve the physical health of workers, in particular in the compound feed production companies, given that in some sectors these companies, there is a lot of dust which causes a malaise on the part of the most sensitive workers. In addition, companies can improve the emotional health of their workers by integrating workers in their relationships with others. The limitations of this study highlights is the cross-sectional nature of the study that may have been carried out in companies in times where the variables could not get the right results. In addition, the characteristics of the sample may not have led to more comprehensive conclusions. From this sample, it is important to identify that the interviewed public consists mainly of men of the masculine gender, with ties to full-time companies and, in most cases, over 40 years of age, which may have influenced levels of commitment. Thus, it will also be important to identify as a limitation the techniques of statistical analysis that, by partial least squares analysis, may have limited conclusions. Thus, it is suggested that in the future other studies in this field should be carried out, in which the limitations found by this research should be taken into account. In this sense, it is suggested that future studies should examine the different types of commitment between persons of the male gender and female gender in industrial companies. It may be important to study the model proposed here in samples of people aged below 30 years old and people over 50 years old to more meaningful conclusions. It may also be important to distinguish firms according to existing leadership styles and draw conclusions from them. 


\section{References}

[1] Adame, C., Caplliure, E.-M., Miquel, M.-J. (2015). Work-life balance and firms: A matter of women? Journal of Business Research. doi: http://dx.doi.org/10.1016/j.jbusres.2015.10.111

[2] Anand, G., Ward, P. T., Tatikonda, M. V., Schilling, D. A. (2009). Dynamic capabilities through continuous improvement infrastructure. Journal of Operations Management, 27(6), 444-461. doi: 10.1016/j.jom.2009.02.002

[3] Bessant, J., Burnell, J., Harding, R., Webb, S. (1993). Continuous improvement in British manufacturing. Technovation, 13(4), 241254. doi: http://dx.doi.org/10.1016/0166-4972(93)90021-M

[4] Bon, A. T., Mustafa, E. M. A. (2013). Impact of Total Quality Management on Innovation in Service Organizations: Literature Review and New Conceptual Framework. Procedia Engineering, 53, 516-529. doi: http://dx.doi.org/10.1016/j.proeng.2013.02.067

[5] Carlton, S. (2015). Reprint of: Connecting, belonging: Volunteering, wellbeing and leadership among refugee youth. International Journal of Disaster Risk Reduction . doi: 10.1016/j.ijdrr.2015.10.010

[6] Cavanaugh, L. A., Leonard, H. A., Scammon, D. L. (2008). A tail of two personalities: How canine companions shape relationships and well-being. Journal of Business Research, 61(5), 469-479. doi: http://dx.doi.org/10.1016/j.jbusres.2007.07.024

[7] Chen, Z. X., Francesco, A. M. (2003). The relationship between the three components of commitment and employee performance in China. Journal of Vocational Behavior, 62(3), 490-510. doi: http://dx.doi.org/10.1016/S0001-8791(02)00064-7

[8] Churchill, G. A. (1979). A paradigm for developing better measures of marketing constructs. Journal of Marketing Research, 16(February), 64-73.

[9] Cronbach, L. J. (1951). Coefficient alpha and the internal structure of tests. Psychometrika, 22(3), $297-334$.

[10] Cunningham, J., Seaman, C., McGuire, D. (2015). Knowledge sharing in small family firms: A leadership perspective. Journal of Family Business Strategy. doi: http://dx.doi.org/10.1016/j.jfbs.2015.10.002

[11] Darcy, C., McCarthy, A., Hill, J., Grady, G. (2012). Work-life balance: One size fits all? An exploratory analysis of the differential effects of career stage. European Management Journal, 30(2), 111-120. doi: http://dx.doi.org/10.1016/j.emj.2011.11.001

[12] Das, A., Kumar, V., Kumar, U. (2011). The role of leadership competencies for implementing TQM: An empirical study in Thai manufacturing industry. International Journal of Quality \& Reliability Management, 28(2), 195-219. doi: doi:10.1108/02656711111101755

[13] Ertosun, Ö. G., Erdil, O. (2012). The Effects of Loneliness on Employees' Commitment and Intention to Leave. Procedia - Social and Behavioral Sciences, 41, 469-476. doi: http://dx.doi.org/10.1016/j.sbspro.2012.04.057

[14] Fornell, C., Larcker, D. F. (1981). Evaluating structural equation models with unobservable variables and measurement error. Journal of Marketing Research, 18(1), 39-50.

[15] Genevičiūtė-Janonienè, G., Endriulaitienè, A. (2014). Employees' Organizational Commitment: Its Negative Aspects for Organizations. Procedia - Social and Behavioral Sciences, 140, 558-564. doi: http://dx.doi.org/10.1016/j.sbspro.2014.04.470

[16] Haar, J. M., Russo, M., Suñe, A., Ollier-Malaterre, A. (2014). Outcomes of work-life balance on job satisfaction, life satisfaction and mental health: A study across seven cultures. Journal of Vocational Behavior, 85(3), 361-373. doi: http://dx.doi.org/10.1016/j.jvb.2014.08.010

[17] Hair, J., Black, W., Babin, B., Anderson, R. (2010). Multivariate Data Analysis: Global Edition (7th ed.). New York: Pearson Higher Education.

[18] Herington, C., Johnson, L. W., Scott, D. (2009). Firm-employee relationship strength-A conceptual model. Journal of Business Research, 62(11), 1096-1107. doi: http://dx.doi.org/10.1016/j.jbusres.2008.06.019

[19] Hoffmeister, K., Gibbons, A., Schwatka, N., Rosecrance, J. (2015). Ergonomics Climate Assessment: A measure of operational performance and employee well-being. Appl Ergon, 50, 160-169. doi: http://dx.doi.org/10.1016/j.apergo.2015.03.011

[20] Huber, T. S. (2014). Professionalism and the work-life balance. Journal of Vascular Surgery, 60(4), 1072-1082. doi: http://dx.doi.org/10.1016/j.jvs.2014.04.077

[21] IACA. (2014). Produção de alimentos compostos para animais em $2014 . \quad$ Retrieved 20-12-2014, 2014, from http://tektix2.com/index.php/o-sector/producao

[22] Jun, M., Cai, S., Shin, H. (2006). TQM practice in maquiladora: Antecedents of employee satisfaction and loyalty. Journal of Operations Management, 24(6), 791-812. doi: http://dx.doi.org/10.1016/j.jom.2005.09.006

[23] Lenka, U., Suar, D., Mohapatra, P. K. J. (2010). Soft and Hard Aspects of Quality Management Practices Influencing Service Quality and Customer Satisfaction in Manufacturing-oriented Services. Global Business Review, 11(1), 79-101. doi: 10.1177/097215090901100105

[24] Lisboa, J., Augusto, M., Ferreira, P. (2012). Estatística aplicada à Gestão. Lisboa: Vida Económica.

[25] Marôco, J. (2014). Análise de Equações Estruturais (2 ${ }^{\mathrm{a}}$ ed.). Lisboa: ReportNumber.

[26] Meyer, J. P., Stanley, L. J., Parfyonova, N. M. (2012). Employee commitment in context: The nature and implication of commitment profiles. Journal of Vocational Behavior, 80(1), 1-16. doi: http://dx.doi.org/10.1016/j.jvb.2011.07.002

[27] Pestana, M., Gageiro, J. (2008). Análise de Dados para Ciências Sociais. Lisboa: Edições Silabo.

[28] Sagie, A. (1998). Employee Absenteeism, Organizational Commitment, and Job Satisfaction: Another Look. Journal of Vocational Behavior, 52(2), 156-171. doi: http://dx.doi.org/10.1006/jvbe.1997.1581

[29] Süß, S., Sayah, S. (2013). Balance between work and life: A qualitative study of German contract workers. European Management Journal, 31(3), 250-262. doi: 10.1016/j.emj.2012.12.003

[30] Trkman, P. (2010). The critical success factors of business process management. International Journal of Information Management, 30(2), 125-134. doi: http://dx.doi.org/10.1016/j.ijinfomgt.2009.07.003

[31] Văcar, A., Miricescu, D. (2013). Leadership - A Key Factor to a Succesful Organization - Part II. Procedia Economics and Finance, 6, 430-435. doi: http://dx.doi.org/10.1016/S2212-5671(13)00159-7

[32] Vieira, A. (2009). ABC do LISREL Interactivo. Lisboa: Edições Sílabo.

[33] Wallace, E., de Chernatony, L., Buil, I. (2013). Building bank brands: How leadership behavior influences employee commitment. Journal of Business Research, 66(2), 165-171. doi: http://dx.doi.org/10.1016/j.jbusres.2012.07.009

[34] White, M., Wells, J. S. G., Butterworth, T. (2014). The impact of a large-scale quality improvement programme on work engagement: Preliminary results from a national cross-sectional-survey of the 'Productive Ward'. International Journal of Nursing Studies, 51(12), 1634-1643. doi: http://dx.doi.org/10.1016/j.ijnurstu.2014.05.002 